\title{
The Role of Adenosine $A_{2 a}$ Receptors in Regulating GABAergic Synaptic Transmission in Striatal Medium Spiny Neurons
}

\author{
Akihisa Mori, Tomomi Shindou, Michio Ichimura, Hiromi Nonaka, and Hiroshi Kase \\ Pharmaceutical Research Laboratories, Kyowa Hakko Kogyo Co., Ltd., Nagaizumi-Cho, Sunto-Gun, \\ Shizuoka 411, Japan
}

We demonstrated an adenosine $\mathrm{A}_{2 \mathrm{a}}$ receptor-mediated disinhibition of medium spiny projection neurons using intracellular recording and the whole-cell patch-clamp recording applied to these cells, visually identified in thin rat striatal slices. The $A_{2 a}$ receptor agonist 2-[p-(2-carboxyethyl) phenylethylamino]-5' $-N$ ethylcarboxamido adenosine (CGS-21680; 0.3-10 $\mu \mathrm{M}$ ) suppressed GABAergic synaptic transmission onto these cells in a manner inhibited by the $A_{2 a}$ receptor-selective antagonist $(E)$ 8-(3,4-dimethoxystyryl)-1,3-dipropyl-7-methylxanthine (0.1-1.0 $\mu \mathrm{M})$. The $A_{1}$ receptor antagonists had no effect on the CGS-
21680 -induced suppression. Analysis of spontaneous miniature inhibitory synaptic currents indicated that suppression of intrastriatal GABAergic synaptic transmission was attributable to presynaptic, but not postsynaptic, $A_{2 a}$ receptors. Therefore, the $A_{2 a}$ receptor may regulate striatal output activity by relieving GABA-mediated inhibition of the medium spiny projection neurons, which explains the ability of purinergic agents to affect motor control.

Key words: adenosine; adenosine receptor; $G A B A ;$ striatum; CGS-21680; KF17837; IPSP; IPSC; CAMP
There is a growing body of evidence that adenosine is a potent inhibitor of neuronal activity in the central and peripheral nervous systems (Nicoll et al., 1990). Four major subtypes of adenosine receptors, $A_{1}, A_{2 a}, A_{2 b}$, and $A_{3}$, have been characterized (for review, see Abbracchio et al., 1993). Among these subtypes, only $A_{1}$ receptors have been known to modulate synaptic transmission in the mammalian CNS (for review, see Fredholm and Dunwiddie, 1988).

In contrast to the widespread distribution of the $A_{1}$ and $A_{2 b}$ receptors in brain, $A_{2 a}$ receptors appear to be confined to the striatum, nucleus accumbens, and olfactory tubercle (Jarvis and Williams, 1989; Parkinson and Fredholm, 1990; Martinez-Mir et al., 1991). This discrete distribution of the $A_{2 a}$ receptor suggests a specific functional role of the $\mathrm{A}_{2 \mathrm{a}}$ receptor in neuronal communication in these areas. In the striatum, which is a major component of the basal ganglia, recent in situ hybridization studies have detected the mRNA encoding the $\mathrm{A}_{2 \mathrm{a}}$ receptor only in the medium spiny neurons (MSNs) (Schiffmann et al., 1990, 1991a,b).

The MSNs are the principal striatal output neurons, making up 90-95\% of the neuronal population in this area, and they send GABAergic axons onto the globus pallidus and substantia nigra. I hey receive not only massive inputs from the cerebral cortex and other areas but also intrinsic inputs from cholinergic (for review, scc Graybicl, 1990; Gerfen, 1992) and glutamatergic interneurons (Mori et al., 1994b,c). The GABAergic synapse onto MSNs is believed to be intrinsic and to originate from either extensive axon collaterals of MSNs or GABAergic interneurons, forming intrastriatal inhibitory circuits. In these circuits, the release of GABA

\footnotetext{
Received May 22, 1995; revised Oct. 2, 1995; accepted Oct. 16, 1995.

We thank J. Shimada for providing KF17837 and KF15372, K. Koga and M. Kurokawa for scientific insights, P. J. Richardson (Cambridge, UK) and P. Jenner (London, UK) for critical comments on this manuscript, H. Kasai (Tokyo, Japan) for providing sottware for data analysis, and I'. Hirata for encouragement.

Correspondence should be addressed to Hiroshi Kase, Pharmaceutical Research Laboratories, Kyowa Hakko Kogyo Company, 1188 Shimotogari, Nagaizumi-Cho, Sunto-Gun, Shizuoka 411, Japan.

Copyright (C) 1996 Society for Neuroscience $0270-6474 / 96 / 160605-07 \$ 05.00 / 0$
}

appears to be regulated tightly by an unidentified neuroactive substance(s) (for review, see Kita, 1993). However, the precise roles of these collaterals and interneurons have not been determined; nor have the mechanisms regulating GABA release from their nerve terminals been described.

Because the $A_{2 a}$ receptor is restricted to the MSNs, we hypothesized that adenosine, via $A_{2 a}$ receptors, regulates $G A B A$-containing synapse activity. To test this hypothesis, we examined GABAergic transmission onto the MSNs, using intracellular recording and whole-cell patch-clamp recording in striatal slices. To identify the $\mathrm{A}_{2 \mathrm{a}}$ receptor-mediated mechanism, we used the newly developed $\mathrm{A}_{2 \mathrm{a}}$ receptor-selective antagonist $(E)$-8-(3,4-dimethoxystyryl)1,3-dipropyl-7-methylxanthine (KF17837) (Nonaka et al., 1994a,b) and the $\mathrm{A}_{2 \mathrm{a}}$ receptor-selective agonist 2-[p-(2-carboxyethyl) phenylethylamino]-5'- $N$-ethylcarboxamido adenosine (CGS-21680) (Jarvis et al., 1989).

In this study, we have found that the $\mathrm{A}_{2 \mathrm{a}}$ receptor serves to suppress GABAergic transmission in the striatal MSNs. The suppression was mimicked by membrane permeable cAMP analogs. Furthermore, we analyzed spontaneous miniature synaptic transmission to determine that this suppression is mediated via presynaptic $A_{2 a}$ receptors. The results provide evidence supporting the hypothesis that adenosine is a specific neuromodulator of the intrastriatal GABAergic circuits. The implications of these findings are discussed in terms of the physiopathological roles of adenosine in the striatum.

Preliminary results have been reported previously in abstract form (Kase et al., 1994; Mori et al., 1994a).

\section{MATERIALS AND METHODS}

Drugs. KF17837, 8-(dicyclopropylmethyl)-1,3-dipropylxanthine (KF15372), and 8-cyclopentyl-1,3-dipropylxanthine (DPCPX) were synthesized at the Medicinal Chemistry Department of the Pharmaceutical Research Laboratories (Shizuoka, Japan) (Shimada et al., 1992). KF17837 was used as KF17837S (Nonaka et al., 1994a,b). Other reagents were from standard commercial sources.

Electrophysiology. Intracellular recordings from striatal neurons were obtained following methods described previously (Kita et al., 1984; Shindou et al., 1994) using a Neurodata IR 183 amplifier (Cabin John, MD). Striatal 
slices $(400 \mu \mathrm{m})$ were prepared from adult Wistar rats. Slices were preincubated in an extracellular solution containing (in $\mathrm{mm}$ ): $120 \mathrm{NaCl}, 3 \mathrm{KCl}, 2.5$ $\mathrm{CaCl}_{2}, 1.2 \mathrm{MgCl}_{2}, 23 \mathrm{NaHCO}_{3}, 1.3 \mathrm{NaH}_{2} \mathrm{PO}_{4}$, and 11 D-glucose with $95 \%$ $\mathrm{O}_{2} / 5 \% \mathrm{CO}_{2}$ at $32^{\circ} \mathrm{C}$ for $1.5 \mathrm{hr}$. Slices then were perfused with this solution supplemented with 6-cyano-7-nitroquinoxaline-2,3-dione (CNQX; $10 \mu \mathrm{M})$, DL-2-amino-5-phosphonovalerate (APV; $100 \mu \mathrm{M})$, and atropine $(10 \mu \mathrm{M}$ ). Drugs were dissolved in dimethylsulfoxide (DMSO) and bath-applied; final concentration of DMSO was adjusted to $0.11 \%$. The extracellular solution containing the same concentration of DMSO was used as a vehicle. At this concentration, DMSO had little effect on IPSPs and IPSCs. The surface of the striatal slice was free of extracellular solution (flow rate $1.5 \mathrm{ml} / \mathrm{min}$ ) and directly exposed to a humidified $\mathrm{O}_{2} / \mathrm{CO}_{2}$ gas mixture. The recording electrode contained $2 \mathrm{M} \mathrm{KCl}$. Synaptic potentials were evoked by focal stimulation $(0.1 \mathrm{~Hz}, 0.1 \mathrm{msec}, 2-5 \mathrm{~V})$ using a bipolar electrode placed within $1.5 \mathrm{~mm}$ of the recording site. All potentials were sampled at $5 \mathrm{~Hz}$ and were stored to a PC (PC9801DS, NEC).

The whole-cell patch-clamp recordings, as described in detail previously (Mori et al., 1994b), were performed in thin horizontal slices $(180-200 \mu \mathrm{m})$ prepared from the striatum of 9- to 12-d-old Wistar rats, directly visualizing cells using an upright Nomarski microscope with a $40 \times$ water immersion objective (Optiphoto, Nikon, Tokyo, Japan). The conditions of slice preincubation, the composition of extracellular solution, and the procedure for drug application were similar to those of intracellular recordings described above. The speed of bath application was $\sim 2 \mathrm{ml} / \mathrm{min}$ in a slice chamber volume of $0.7 \mathrm{ml}$. The pipette (6-12 M 2 ) contained (in mM): $140 \mathrm{CsCl}, 10$ HEPES, $1 \mathrm{MgCl}_{2}, 2 \mathrm{Mg}$-ATP, and $0.2 \mathrm{Cs-EGTA,} \mathrm{pH-adjusted} \mathrm{to} 7.2$ with $\mathrm{CsOH}$. The series resistance during the whole-cell configuration was $15-40$ $\mathrm{M} \Omega$. Membrane currents were recorded at $-70 \mathrm{mV}$ and were amplified and filtered at $2 \mathrm{kHz}$ (Axopatch 1-D, Axon Instruments, Foster City, CA). Synaptic currents were evoked by focal stimulation $(0.2 \mathrm{~Hz}, 0.2 \mathrm{msec}, 20-100$ V) delivered via a glass micropipette (tip diameter 5-10 $\mu \mathrm{m}$ ) filled with the extracellular solution and positioned within $150 \mu \mathrm{m}$ of the recorded cell. Under these conditions, the currents were inverted at $0 \mathrm{mV}$, close to the chloride equilibrium potential $\left(E_{C \mathrm{C}}\right)$. All currents were sampled at $10 \mathrm{kHz}$ and stored on a PC (PC9801DS, NEC). Drug effects on IPSCs were evaluated from the averaged IPSC amplitude. The experiments showing no recovery of IPSC amplitude after washout of the drugs were omitted.

Spontaneous miniature IPSCs (mIPSCs) in the MSNs were recorded with $1.0 \mu \mathrm{M}$ tetrodotoxin (TTX) added to the extracellular solution. These currents almost completely disappeared after application of bicuculline (data not shown). Onset of IPSCs was determined by eye, and events that had amplitudes of $<4.5 \mathrm{pA}$ or that showed time-to-peak longer than decay were omitted from the analysis. Events were ranked by amplitude for preparation of cumulative probability distributions. Statistically significant difference was assessed by the Kolmogorov-Smirnov test (Van der Kloot, 1991), which considers both the maximum difference between the two distributions and the number of sampled events. The test calculates the likelihood that the two data sets are drawn from the same distribution, that is, the probability $(p)$ that a difference larger than that observed would occur by chance. The higher the calculated $p$, the more likely that the observed curves are not different. We have chosen to define stringently two distributions to be not significantly different only at $p>$ 0.05 . All measurements were performed at room temperature $\left(23-26^{\circ} \mathrm{C}\right)$. All values are expressed as mean \pm SEM.

cAMP assay in striatal slices. cAMP level in rat brain slices was measured by a method described previously (Garthwaite and Garthwaite, 1987), with modifications. Perahorizontal slices ( $400 \mu \mathrm{m}$ thick) of the striatum were prepared from male 35- to 40-d-old Wistar rats. The slices were incubated at $32^{\circ} \mathrm{C}$ in a Krebs'-Ringer's solution, gassed with $95 \%$ $\mathrm{O}_{2} / 5 \% \mathrm{CO}_{2}$ at $32^{\circ} \mathrm{C}$. The slices were preincubated for $2 \mathrm{hr}$. Drugs were dissolved in DMSO and then added at appropriate concentrations (final concentration of DMSO, $0.1 \%$ ). After a 5 min exposure to drugs, treated slices were withdrawn and inactivated by boiling for $5 \mathrm{~min}$ in $50 \mathrm{~mm}$ Tris $/ 4$ mM EDTA buffer, pH 7.6. cAMP levels in the supernatants obtained after sonication and centrifugation $\left(7000 \times g, 10 \mathrm{~min}, 4^{\circ} \mathrm{C}\right.$ ) were measured with radioimmunoassay kits (Yamasa, Tokyo, Japan). Proteins were measured with a protein assay kit (Bio-Rad, Richmond, CA) with bovine serum albumin as the standard.

\section{RESULTS}

The adenosine $A_{2 a}$ receptor agonist CGS-21680 reduces evoked GABAergic IPSPs in striatal neurons

Evoked IPSPs were elicited by focal stimulation, and intracellular recordings were made from neurons in slices of adult rat striatum.
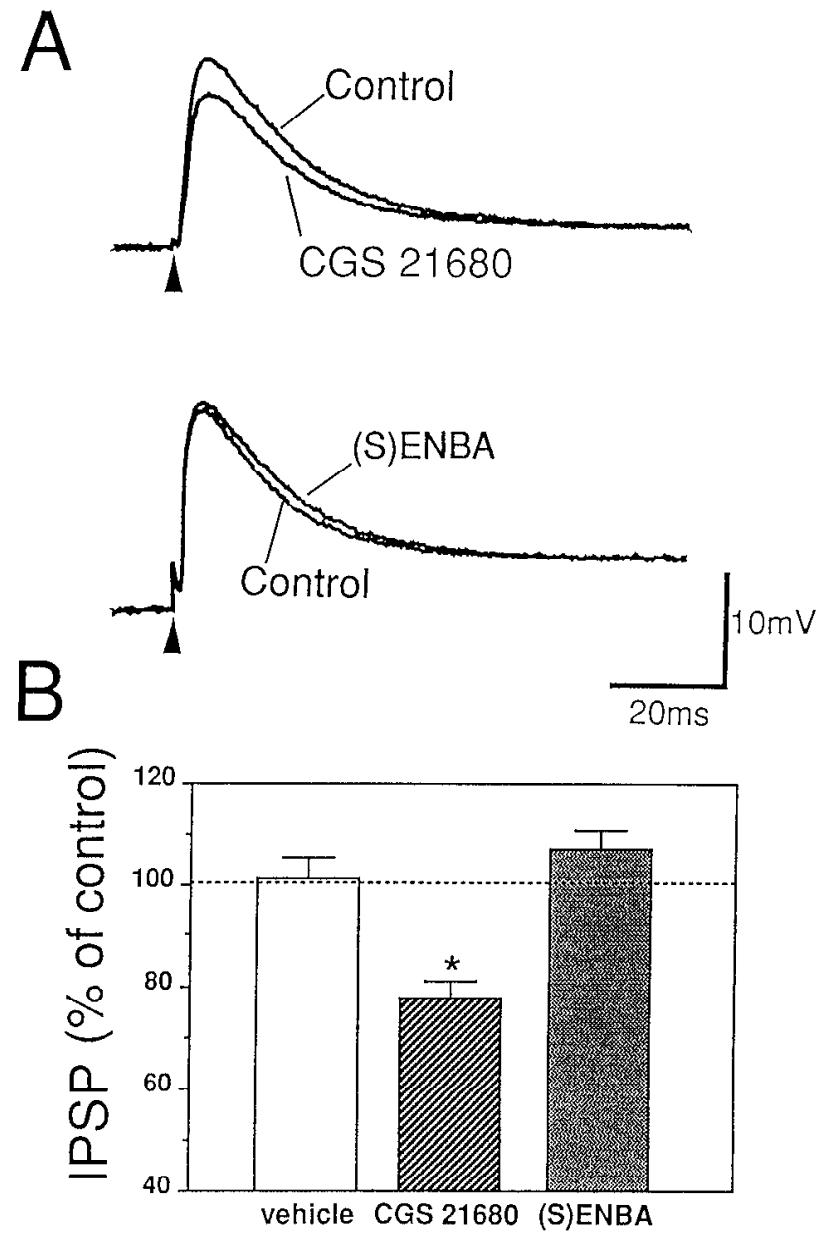

Figure 1. The adenosine $\mathrm{A}_{2 \mathrm{a}}$ receptor agonist suppresses GABAergic IPSPs in striatal neurons. Effects of the $\mathrm{A}_{1}$ receptor agonist $(S)$ ENBA and the $\mathrm{A}_{2 \mathrm{a}}$ receptor agonist CGS-21680 un GABAergic IPSPs recorded using intracellular recordings from striatal slices. The recordings were made in current clamp with the resting membrane potential maintained between -70 and $-75 \mathrm{mV}$. A, Typical superimposed averaged traces of 10 consecutive IPSPs before (Control) and during the application of $1 \mu \mathrm{M}$ CGS-21680 (top) or $0.3 \mu \mathrm{M}(S)$ ENBA (bottom). B, CGS-21680 $(1 \mu \mathrm{M})$ reduced peak amplitude of IPSPs, and $(S)$ ENBA $(0.3 \mu \mathrm{M})$ had no effect. Data represent percentage of control and mean \pm SEM (bars) values. Vehicle application did not affect the amplitude of IPSPs $(101 \pm 4 \%$ of control; $n=4$ ); ${ }^{*} p<0.05$ versus vehicle by Scheffe test. All pooled data were obtained comparing the peak amplitude of averaged IPSPs (10 traces) in control and during drug application.

Excitatory glutamate and muscarinic acetylcholine receptors were blocked by the addition of CNQX $(10 \mu \mathrm{M})$, APV $(100 \mu \mathrm{M})$, and atropine $(10 \mu \mathrm{M})$. Recorded IPSPs were shown to be mediated by $\mathrm{GABA}_{\mathrm{A}}$ receptors because they were blocked by bicuculline ( 30 $\mu \mathrm{M}$; data not shown). These GABAergic IPSPs were reduced in amplitude by depolarization, increased by hyperpolarization, and reversed polarity between -50 and $-60 \mathrm{mV}$. The average value of the peak IPSP amplitude in controls was $12.6 \pm 0.7 \mathrm{mV}(n=29)$. The $A_{2 \mathrm{~d}}$ receptor-selective agonist CGS-21680 $(1 \mu \mathrm{M})$ significantly reduced the peak IPSP amplitude to $78 \pm 3 \%$ of control $(p<0.05$; $n=12$ ) without changing the resting membrane potential or the time course of the IPSP (Fig. 1A, top, $B$ ). The amplitude, however, was barely affected by the $A_{1}$ receptor-selective agonist $N^{6}-(2 S)$ [2-endo-norbornyl]adenosine [(S)ENBA] (Trivedi et al., 1989) at 


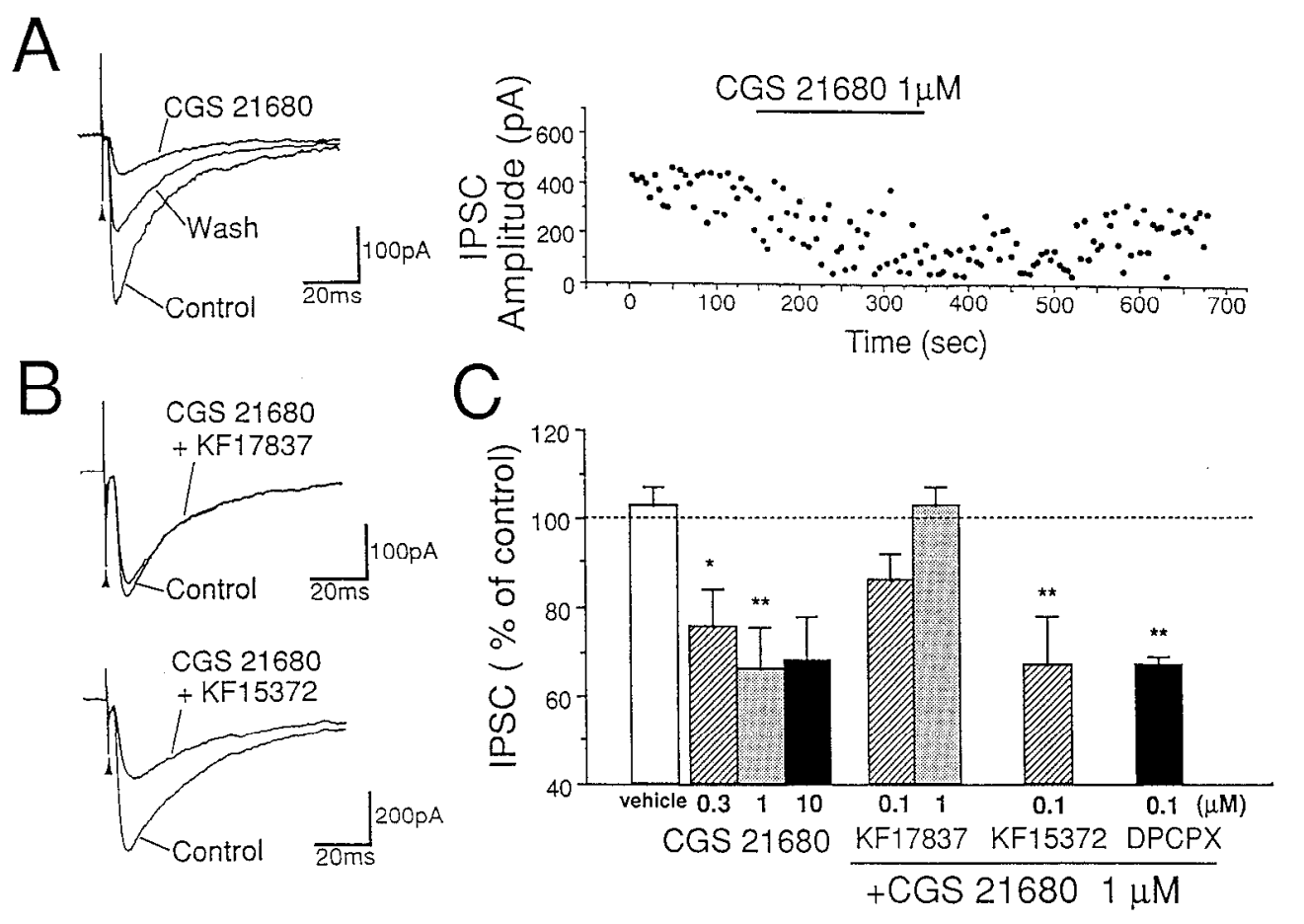

Figure 2. The adenosine $A_{2 a}$ receptor selectively suppresses GABAergic IPSCs in striatal MSNs. Effects of CGS21680 alone and coapplication of CGS21680 with the $A_{1}$ receptor antagonists KF15372 or DPCPX or with the $A_{2}$ receptor antagonist KF17837 on striatal GABAergic IPSCs recorded by using the whole-cell patch-clamp method from the MSNs in striatal slices. $A$, Superimposed traces of an average of consecutive IPSCs (15 traces) before (Control), during, and after (Wash) application of CGS-21680 (1 $\mu \mathrm{M} ;$ left $)$ and a representative time course (right). The slow onset and incomplete recovery may be attributable to solution exchange. $B$, Typical superimposed traces of average of consecutive IPSCs (12 traces) before (Control) and during coapplication of CGS-21680 (1 $\mu \mathrm{M})$ with KF17837 (0.1 $\mu \mathrm{M}$; top) or with KF15372 $(0.1 \mu \mathrm{M} ;$ bottom $) . C$, Pooled data showing that the suppression by CGS-21680 of IPSCs was dose-dependent (0.3-1 $\mu \mathrm{M})$ and was blocked selectively by KF17837. Data represent percentage of control and mean \pm SEM (bars) values. Vehicle application had no effect on amplitude of IPSCs $(103 \pm 4 \%$ of control; $n=15) ;{ }^{*} p<0.05 ; * * p<0.01$ versus vehicle by Scheffe test. $\Lambda 11$ pooled data were obtained by comparing averaged IPSCs (12-15 traces) before and during drug application.
$0.3 \mu \mathrm{M}(107 \pm 4 \%$ of control, $n=4$; Fig. $1 A$, bottom, B), a concentration that is shown to be effective on striatal $A_{1}$ receptors via its action on glutamatergic synaptic transmission in the striatum (our unpublished data). These results suggest that adenosine $A_{2 \mathrm{a}}$ receptors serve to suppress $\mathrm{GABA}$ receptor-mediated inhibitory inputs onto striatal neurons.

\section{The adenosine $A_{2 a}$ receptor mediates inhibition of evoked GABAergic IPSCs in the MSNs}

To verify the above finding, we measured evoked IPSCs with whole-cell patch-clamp recording from an MSN. We chose only small spiny neurons with a diameter of $<13 \mu \mathrm{m}$. Injection of Lucifer yellow (Sigma, St. Louis, MO) into these neurons revealed the following characteristic features of the MSNs. The cells projected several fine, 100 - to $250-\mu \mathrm{m}$-long dendrites in all directions. Fine, spiny structures were observed when cells were located close to the surface. In the presence of CNQX, APV, and atropine in the external solution and a high concentration of $\mathrm{Cl}^{-}$in the pipette solution, the MSNs displayed inward currents evoked by the focal stimulation at a holding potential of $-70 \mathrm{mV}$. Under these conditions, recorded intrastriatal IPSCs were confirmed to be mediated by $\mathrm{GABA}_{\mathrm{A}}$ receptors via antagonism with bicuculline (30 $\mu \mathrm{M})$ or picrotoxin $(100 \mu \mathrm{M}$; data not shown). The average values (mean $\pm \mathrm{SEM}$ ) of peak amplitude (in $\mathrm{pA}$ ), latency (in $\mathrm{msec}$ ), time-to-peak (in msec), and time constant of decay (in $\mathrm{msec})$ at $-70 \mathrm{mV}$ in control were $406+25(n=67), 2.9+0.1(n$ $=33), 3.1 \pm 0.1(n=33)$, and $30.6 \pm 0.9(n=33)$, respectively. CGS-21680 significantly reduced the averaged amplitude of evoked IPSCs within 2 min of application of the drug (Fig. 2A, right) without affecting the time course of the IPSCs (Fig. 2A, left). After drug removal, the IPSC amplitude slowly recovered. The suppression of IPSCs by CGS-21680 was concentration- dependent and saturated at $1 \mu \mathrm{M}: 76 \pm 8 \%(p<0.05 ; n=11), 66$ $\pm 10 \%(p<0.01 ; n=7)$, and $68 \pm 10 \%(n=3)$ of control at 0.3 , 1.0, and $10 \mu \mathrm{M}$ CGS-21680, respectively (Fig. 2C). The $A_{2 a}$ receptor-selective antagonist $\mathrm{KF} 17837$, when applied together with $1 \mu \mathrm{M}$ CGS-21680, blocked the inhibitory effect of CGS-21680 in a concentration-dependent manner: the IPSC amplitudes were $86 \pm 7 \%(n=6)$ and $103 \pm 4 \%(n=8)$ of control at 0.1 and $1 \mu \mathrm{M}$ KF17837, respectively. Two different $A_{1}$ receptor-selective antagonists, DPCPX and KF15372, had no effect on the CGS-21680 (1 $\mu \mathrm{M}$ )-induced suppression of the IPSCs at $0.1 \mu \mathrm{M}$ concentration (Fig. 2B,C). For both antagonists, this concentration is sufficient to block $A_{1}$ receptors (Lolise el al., 1987; Suzuki et al., 1992). These results demonstrate the existence of $\mathrm{A}_{2 \mathrm{a}}$ receptor-mediated modulation of striatal GABA transmission in the MSNs. Furthermore, KF17837 alone dose-dependently enhanced the IPSC amplitude: $107 \pm 16 \%(n=3), 122 \pm 14 \%(n=4)$, and $140 \pm 19 \%$ $(n=4)$ of control at 1,3 , and $10 \mu \mathrm{M}$ of KF17837, respectively. This indicated that endogenous adenosine, present within the striatal slice, suppressed GABA receptor-mediated inhibitory input onto striatal neurons.

\section{Modulation of GABAergic synaptic transmission in the MSNs is mediated by presynaptic adenosine $A_{2 a}$ receptors}

To investigate whether the regulation of the striatal GABAergic synaptic transmission in the MSNs was mediated by post- and/or presynaptic $A_{2 \text { ad }}$ receptors, we analyzed the spontaneous mIPSCs in the striatal slices. Spontaneous mIPSCs were recorded as inward currents from MSNs in the striatal slices (see Fig. 3A, left). These currents ranged from 5 to $>75 \mathrm{pA}$ in amplitude at a holding potential of $-70 \mathrm{mV}$, and the basal mean frequencies were 
Figure 3. The adenosine $\mathrm{A}_{7 \mathrm{n}}$ receptor agonist and antagonist affect GABA synapses onto MSNs at presynaptic, but not postsynaptic, sites. A: Ieft, Typical traces of spontaneous mIPSCs recorded from an MSN are shown with each 10 sweeps at the left (Con$(\mathrm{rol})$ and 10 sweeps at the right (during $1 \mu \mathrm{M}$ CGS-21680 application). Cumulative probability distributions of mIPSC amplitude in control (175 events) and in $1 \mu \mathrm{m}$ CGS-21680 (142 events), constructed from the same data, are shown on the right. There was no statistically significant difference between these distributions, as assessed by the Kolmogorov-Smirnov test $(p>0.4)$. The frequencies (in $\mathrm{Hz}$ ) and amplitudes (mean 士 $\mathrm{SD}$, in $\mathrm{pA}$ ) of mIPSCs were 1.05 and $27.5 \pm$ 11.8 in control and 0.66 and $27.7+13.2$, in CGS-21680 application, respectively. $B$, Pooled data showing that CGS-21680 (1 $\mu \mathrm{M})$ decreased and KF17837 (10 $\mu \mathrm{M})$ increased the mean frequency, without affecting the mean amplitude of mIPSCs. Data represent percentage of control and mean \pm SEM (bars) values. Control values of the frequency (in $\mathrm{Hz}$ ) and mean amplitude (in $\mathrm{pA}$ ) of $\mathrm{mIP}$ SCs were $0.79 \pm 0.13$ and $23.4 \pm 2.5$ in the CGS21680 experiment $(6$ cells) and $0.71 \pm$ 0.13 and $19.7 \pm 1.00$ in the KF17837 experiment ( 4 cells), respectively. $C$, Typical traces of $\mathrm{GABA}_{\mathrm{A}}$ receptor-mediated depolarizing action of striatal neurons recorded intracellularly showing that CGS-21680 $(10 \mu \mathrm{M})$ had no effect on the actions. GABA (10 mM) was bath-applicd.
A
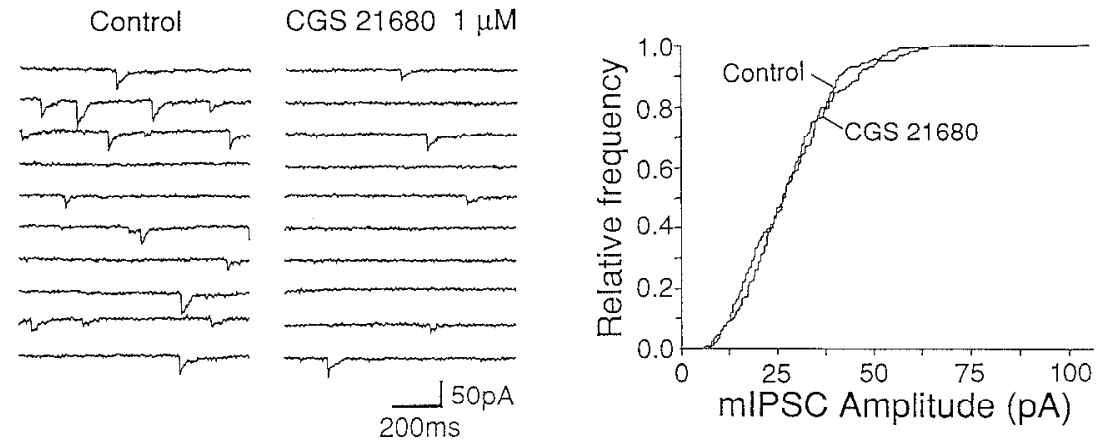

$B$

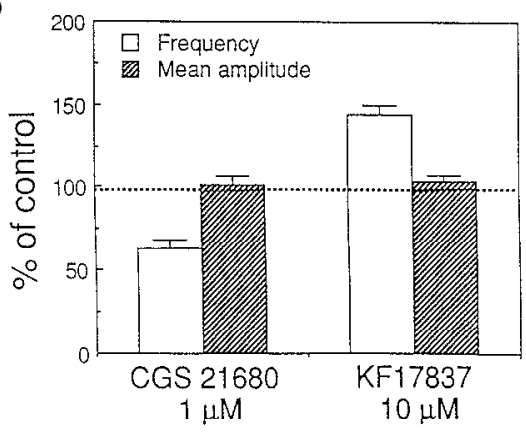

C

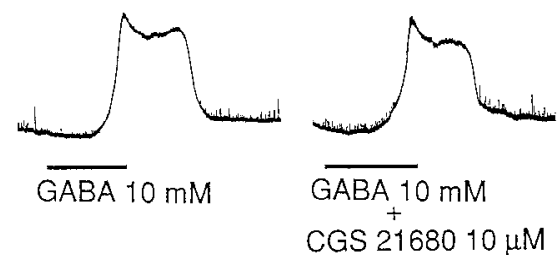

$\left.20 \mathrm{mv}\right|_{2 \mathrm{~min}}$ between 0.4 and $1.4 \mathrm{~Hz}$, depending on the slice preparations. These currents completely disappeared after application of bicuculline (data not shown), indicating that the mIPSCs were mediated entirely by GABA $\mathrm{A}_{\mathrm{A}}$ receptors. CGS-21680 $(1 \mu \mathrm{M})$ decreased the mean frequency of mIPSCs from $0.79 \pm 0.13$ to $0.50 \pm 0.09 \mathrm{~Hz}$ ( $63 \pm 5 \%$ of control, $p<0.01$ by paired $t$ test $n=6$ ), whereas the mean amplitude was not changed (mean amplitude in the presence of CGS-21680: $23.2 \pm 2.0 \mathrm{pA}, 101 \pm 6 \%$ of control, $n=6$; Fig. $3 B$ ). The decrease in the mean frequency slowly recovered after drug removal. In four cells, we were able to collect sufficient numbers of currents for the distribution analysis. There was no significant change in these mIPSC-amplitude distributions as determined by the Kolmogorov-Smirnov test. The typical data are shown in Figure $3 A$. In striking contrast to the effects of CGS21680 on mIPSCs, $10 \mu \mathrm{M} \mathrm{KF17837} \mathrm{increased} \mathrm{the} \mathrm{mean} \mathrm{frequency}$ of mIPSCs from $0.71 \pm 0.13$ to $1.00 \pm 0.33 \mathrm{~Hz}(144 \pm 6 \%$ of control, $p<0.01$ by paired $t$ test; $n=4)$. In these cells, KF17837 caused no significant change in either the mean amplitude (20.4 \pm $1.24 \mathrm{pA}, 104 \pm 4 \%$ of control; Fig. $3 B$ ) or the amplitude distribution. These results indicated that CGS-21680 reduced and KF17837 increased the quantal release of transmitter from the presynaptic terminals. To support this conclusion, we examined the effect of CGS-21680 on GABA-induccd depolarizing action using intracellular recordings from striatal slices. GABA was bath-applied and, thus, was significantly diluted before reaching the cell membrane. Therefore, $10 \mathrm{~mm}$ GABA was used so that a similar amplitude of evoked IPSPs and reproducible depolarizations could be obtained with repeated application. The depolarizing action by bath-applied GABA (10 mM) was confirmed to be mediated by $\mathrm{GABA}_{\mathrm{A}}$ receptors via antagonism with bicuculline (50 $\mu \mathrm{M}$; data not shown). CGS-21680 had no effect on the peak amplitude of GABA-induced depolarizing action: $100 \pm 5 \%(n=$ 4) and $98 \pm 6 \%(n=3)$ of control at 1 and $10 \mu \mathrm{M}$, respectively (Fig. $3 C$ ). These results demonstrate that the suppression of GABAergic synaptic transmission in the MSNs was made by presynaptic, but not postsynaptic, $A_{2 a}$ receptors.

\section{Effect of cAMP analogs on IPSCs}

The $A_{2}$ receptor is known to be coupled positively to adenylate cyclase (Van Calker et al., 1979). Corresponding with the results reported previously (Lupica et al., 1990; Hide et al., 1992), CGS$21680(1 \mu \mathrm{M})$ actually increased cAMP accumulation in rat striatal slices from the control level of $15.1 \pm 1.1 \mathrm{pmol} / \mathrm{mg}$ protein $(n=$ $12)$ to $32.2 \pm 4.8 \mathrm{pmol} / \mathrm{mg}$ protein $(n=3)$. KF17837 $(0.1-0.3 \mu \mathrm{M})$ suppressed the increase of cAMP level to the control level dosedependently (data not shown), indicating that CGS-21680induced cAMP increase is mediated by the $\mathrm{A}_{2 \mathrm{a}}$ receptor. These results suggested that $c A M P$ mediated the synaptic regulation of GABAergic transmission by the $A_{2 a}$ receptor. Therefore, we studied the effect of cAMP on GABAergic synaptic transmission using membrane-permeable cAMP analogs. 8-Bromo-cAMP and dibutyryl cAMP $(0.5 \mathrm{mM})$ reversibly suppressed the IPSC amplitude to $69 \pm 5 \%(n=8)$ and $52 \pm 7 \%(n=3)$ of control, respectively (Fig. $4 A, B$ ).

\section{DISCUSSION}

\section{Presynaptic $A_{2 a}$ receptor-mediated suppression of GABAergic synaptic transmission in the MSNs}

A fragile balance between excitation and inhibition maintains the neuronal functioning of the CNS. Modulation of excitation and/or inhibition has substantial implications for both normal physiolog- 

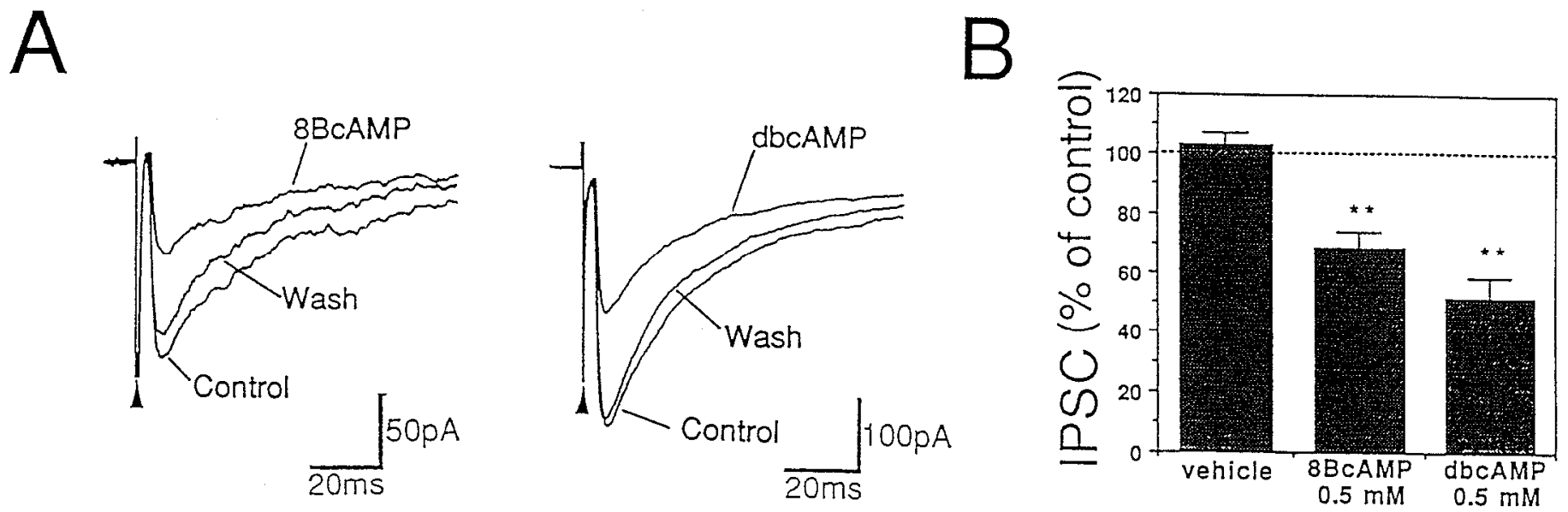

Figure 4. Involvement of cAMP-signaling pathway with the regulation of GABAergic synaptic transmission in the striatum. $A$, Typical superimposed traces of an average of consecutive IPSCs (12 traces) before (Control), during, and after (Wash) applications of 8-bromo-cAMP (8BcAMP, left) and dibutyryl cAMP ( $d b c A M P$, right), each at $0.5 \mathrm{mM}$, showing that both analogs reversibly suppressed IPSCs. $B$, Pooled data for suppression of 8-bromo-cAMP $(n=8)$ and dibutyryl cAMP $(n=3)$ on IPSC amplitude; ** $p<0.01$ versus vehicle by Schefte test. Vehicle group is similar to that shown in Figure 2.

ical processes and pathological states of brain function. Many reports have shown that adenosine suppresses excitatory synaptic transmission through the $A_{1}$ receptors. In the present report, we demonstrate for the first time that the adenosine $\mathrm{A}_{2 \mathrm{a}}$ receptor suppresses inhibitory synaptic transmission in the mammalian CNS. One particularly important finding is that the inhibitory action of adenosine was shown in the major output neurons of the striatum.

Suppression of GABAergic synaptic transmission by an $A_{2.4}$ receptor-mediated mechanism in the MSNs was demonstrated in this study by adapting the intracellular recording and the highresolution patch-clamp recording technique to striatal slices, directly visualizing these cells. In addition, we used CGS-21680 and KF17837, selective agents for $A_{2 \mathrm{a}}$ receptors. Both of these agents have been shown to be selective for $A_{2 a}$ receptors in membranebinding and autoradiographic assays (Jarvis and Williams, 1989; Parkinson and Fredholm, 1990; Martinez-Mir et al., 1991; Nonaka et al., 1994a,b). The GABA ${ }_{\mathrm{A}}$-mediated IPSPs or IPSCs were elicited by a stimulating electrode placed in the vicinity of the recording site, under conditions in which excitatory inputs were blocked, so that the effects of selective adenosine agonists and/or antagonists on GABA-mediated inhibition could be observed without complications caused by excitatory transmission. The GABAergic neurotransmission was examined further by analysis of mIPSCs caused by spontaneous release of GABA from presynaptic terminals in the presence of TTX to block the propagation of action potentials to the terminals. Both IPSPs and IPSCs were suppressed significantly by CGS-21680 (Figs. 1, 2, 3A,B). KF17837 blocked the effect of CGS-21680 (Fig. 2B,C) and alone enhanced the evoked IPSCs. The selective $\mathrm{A}_{2 \mathrm{a}}$ agonist and antagonist changed the frequency of MIPSCs without affecting either the mean amplitude or the amplitude distributions. This showed a presynaptic action of the $\mathrm{A}_{2 \mathrm{a}}$ receptor, regulating the quantal release of GABA (Fig. $3 A, B$ ). The absence of postsynaptic $\mathrm{A}_{2 \mathrm{a}}$ receptor-mediated control was supported by the finding that CGS-21680 had no effect on the peak amplitude of GABAinduced depolarizing action in striatal neurons (Fig. 3C). Recent neurochemical studies have shown that the $A_{2 a}$ receptor modu- lates $\left[{ }^{3} \mathrm{H}\right] \mathrm{GABA}$ release from globus pallidus slices (Mayfield et al., 1993) and from striatal synaptosomes (Kirk and Richardson, 1994), an effect that was blocked by KF17837 (Kurokawa et al., 1994). These results are consistent with the existence of presynaptic modulation by $A_{2 a}$ receptors of striatal GABA synapses onto MSNs.

The presynaptic $A_{2 a}$ receptor appears to regulate GABAergic inputs to the MSNs via cAMP signaling, because CGS-21680 at 1 $\mu \mathrm{M}$ induced both IPSC suppression (Fig. 2) and cAMP accumulation in the striatal slices, and the amount of IPSC suppression by cAMP analogs was similar to that by CGS-21680 (Figs. 2, 4). In addition, we had preliminary data indicating that dibutyryl cAMP reduces the frequency of mIPSCs, which suggests that the cAMP action is presynaptic. These data suggest that the presynaptic $A_{2 a}$ receptor stimulation is mediated by cAMP accumulation, although further, precise investigation is necessary to strengthen this point.

\section{Physiological significance of the adenosine $A_{2 a}$ receptor-mediated modulation of GABAergic synaptic transmission in the MSNs}

The GABA component of synaptic potentials in the MSNs is attributable either to intrinsic synaptic contact from other MSNs via axon collaterals (Jiang and North, 1991) or to interneurons. Consequently, the recorded IPSPs and IPSCs are attributable either to the GABA synapses caused by other MSNs or to another GABAergic input from the interneurons. GABA released from the axon collaterals would produce strong local mutual inhibition, comprising an intrastriatal inhibitory feedback circuit and thereby providing a mechanism for concentrating the diffused pattern of the various inputs onto the relevant striatum target system. Alternatively, GABA released from the interneurons would serve as part of a striatal feedforward circuit, providing another intrastriatal inhibition mechanism (Kita, 1993).

The modulation of GABAergic synaptic transmission onto the MSNs by adenosine in the striatum suggests, therefore, the following two physiological models. (1) Adenosine is a regulator of GABA release from the collateral axons, and the presynaptic $A_{2 a}$ 
receptor activation causes a reduction in GABA-mediated synaptic inhibition within an intrastriatal feedback circuit. (2) Adenosine regulates GABA release from the interneurons and attenuates the feedforward regulation mechanism. These adenosine receptor-mediated disinhibition mechanisms may influence striatal proccssing of the information from cortex, from other regions of the brain, and from the striatal interneurons to the striatal output pathways on the basal ganglia-thalamocortical circuitry.

Although mRNA encoding the $\mathrm{A}_{2 \mathrm{a}}$ receptor has been detected in a number of MSNs, there is no evidence that GABAergic interneurons express the receptor (Schiffmann et al., 1991a,b). The MSN receives recurrent GABAergic inputs from axon collaterals of neighboring MSNs. Therefore, the presynaptic $A_{2 a}$ receptor-mediated suppression of GABAergic neurotransmission occurred in the recurrent inputs by the receptor-expressing axon collateral terminals of neighboring MSNs. However, Jaeger et al. (1994) have reported recently that the mutual inhibition among MSNs is weak or nonexistent in the rat striatum and have argued against the common view that the intrastriatal inhibitory feedback circuit is a central organizing principle of striatal function. If $\mathrm{A}_{2 \mathrm{a}}$ receptors were expressed in the axon terminal of GABAergic interneuron despite their absence in the cell body, the $A_{2 a}$ receptor-mediated suppression would have occurred in nerve terminals of GABAergic interneurons.

Both the intrastriatal GABAergic feedback circuit led by the MSNs and the feedforward circuit formed between MSNs and interneurons play an important role in temporal and spatial filtering of various input influences from cortex, from other regions of the brain, and from uther striatal interneurons, and they regulate the striatal output activity via inhibition of the projection neurons (Groves, 1983; Kita, 1993). The $\mathrm{A}_{2 \mathrm{a}}$ receptor-mediated regulation mechanisms, therefore, may cause overactivity of the striatal output pathways. Corresponding with this hypothesis, we have demonstrated recently that KF17837 ameliorates motor dysfunction in 6-hydroxydopamine-lesioned rat (K. Koga, M. Kurokawa, S. Shiozaki, M. Ochi, J. Nakamura, and Y. Kuwana, unpublished data), although it remains to be determined whether KF17837 affects the activity of the globus pallidus and/or the substantia nigra.

In conclusion, these data show that presynaptic $A_{2 a}$ receptors modulate GABAergic synaptic transmission onto the MSNs and, therefore, regulate a major feedback circuit and/or feedforward circuit within the striatum. It is likely that this will provide new insights into the physiopathology of adenosine in this area of the brain. We also suggest that this modulation plays an important role in the control of voluntary movement and will provide a new approach to the therapy of Parkinson's disease.

\section{REFERENCES}

Abbracchio MP, Flaminio C, Fredholm BB, Williams M (1993) Purinoceptor nomenclature: a status report. Drug Dev Res 28:207-213.

Fredholm BB, Dunwiddie TV (1988) How does adenosine inhibit transmitter release? Trends Pharmacol Sci 9:130-137.

Garthwaite J, Garthwaite G (1987) Cellular origins of cyclic GMP responses to excitatory amino acid receptor agonists in rat cerebellum in vitro. J Neurochem 48:29-39.

Gerfen CR (1992) The neostriatal mosaic: multiple levels of compartmental organization in the basal ganglia. Annu Rev Neurosci 15:285-320.

Graybiel AM (1990) Neurotransmitters and neuronodulitors in the basal ganglia. Trends Neurosci 13:244-254.

Groves PM (1983) A theory of the functional organization of the neostriatum and the neostriatal control of voluntary movement. Brain Res Rev 5:109-132.
Hide I, Padgett WL, Jacobson KA, Daly JW (1992) A $2: a_{a}$ adenosine receptors from rat striatum and rat pheochromocytoma $\mathrm{PC} 12$ : characterization with radioligand binding and by activation of adenylate cyclase. Mol Pharmacol 41:352-359.

Jaeger D, Kita H, Wilson CJ (1994) Surround inhibition among projection neurons is weak or nonexistent in the rat neostriatum. J Neurophysiol 72:2555-2558.

Jarvis MF, Williams M (1989) Direct autoradiographic localization of adenosine $A_{2}$ receptors in the rat brain using the $A_{2}$-selective agonist $\left[{ }^{3} \mathrm{H}\right] \mathrm{CGS} 21680$. Eur J Pharmacol 168:243-246.

Jarvis MF, Schulz R, Hutchison AJ, Do UH, Sills MA, Williams M (1989) $\left[{ }^{3} \mathrm{H}\right] \mathrm{CGS}-21680$, a selective $\mathrm{A}_{2}$ adenosine receptor agonist directly labels $\mathrm{A}_{2}$ receptors in rat brain. J Pharmacol Exp Ther 251:888-893.

Jiang Z-G, North RA (1991) Membrane properties and synaptic responses of rat striatal neurones in vilro. J Plysiol (Lond) 443:533-553.

Kase H, Mori A, Shindou H, Nonaka H, Ichimura M (1994) Role of adenosine $A_{2 \mathrm{a}}$ receptor in GABAergic synaptic transmission in the striatum (Abstr). Br J Pharmacol 114:300A.

Kita H (1993) GABAergic circuits of the striatum. In: Progress in brain research, Vol 99 (Arbuthnott GW, Emson PC, eds), pp 51-72. New York: Elsevier.

Kita T, Kita H, Kitai ST (1984) Passive electrical membrane properties of rat neostriatal neurons in an in vitro slice preparation. Brain Res 300:129-139.

Kirk IP, Richardson PJ (1994) Adenosine $\mathrm{A}_{2 \mathrm{a}}$ receptor-mediated modulation of striatal $\left[{ }^{3} \mathrm{H}\right] \mathrm{GABA}$ and $\left[{ }^{3} \mathrm{H}\right]$ acetylcholine release. $\mathbf{J}$ Neurochem 62:960-966.

Kurokawa M, Kirk IP, Kirkpatrick KA, Kase H, Richardson PJ (1994) Inhibition by KF17837 of adenosine $A_{2 a}$ receptor-mediated modulation of striatal GABA and ACh release. Br J Pharmacol 113:43-48.

Lohse MJ, Klotz KN, Lindenborn-Fotinos J, Reddington M, Schwabe U, Olsson RA (1987) 8-Cyclopentyl-1,3-dipropylxanthine (DPCPX): a selective high affinity antagonist radioligand for $\mathrm{A} 1$ adenosine receptors. Naunyn Schmiedebergs Arch Pharmacol 336:204-210.

Lupica CR, Cass WA, Zaniser NR, Dunwiddie TV (1990) Effects of the selective adenosine $\mathrm{A}_{2}$ receptor agonist CGS-21680 on in vitro electrophysiology, cAMP formation and dopamine release in rat hippocampus and striatum. J Pharmacol Exp Ther 252:1134-1141.

Martinez-Mir MI, Probst A, Palacios JM (1991) Adenosine $A_{2}$ receptors: selective location in the human basal ganglia and alterations with disease. Neuroscience 42:697-706.

Mayfield RD, Suzuki F, Zahniser NR (1993) Adenosine $A_{2: \mathrm{t}}$ receptor modulation of electrically evoked endogenous GABA release from slices of rat globus pallidus. J Neurochem 60:2334-2337.

Mori A, Shindou T, Kase H (1994a) Role of adenosine $A_{2 a}$ receptor in GABAergic synaptic transmissions in the striatum. Neurosci Res [Suppl] 19:S52.

Mori A, Takahashi T, Miyashita Y, Kasai H (1994b) Two distinct glutamatergic synaptic inputs to striatal medium spiny neurones of neonatal rats and paired-pulse depression. J Physiol (Lond) 476:217-228.

Mori A, Takahashi T, Miyashita Y, Kasai H (1994c) Quantal properties of H-type glutamatergic synaptic input to the striatal medium spiny neurons. Brain Res 654:177-179.

Nicoll RA, Malenka R, Kauer JA (1990) Functional comparison of neurotransmitter receptor subtypes in mammalian central nervous system. Physiol Rev 70:513-565.

Nonaka H, Ichimura M, Takeda M, Nonaka Y, Shimada J, Suzuki F, Yamaguchi K, Kase H (1994a) KF17837 [(E)-8-(3,1-dimethoxystyryl) 1,3-dipropyl-7-methylxanthine], a potent and selective adenosine $\mathrm{A}_{2}$ receptor antagonist. Eur J Pharmacol 267:335-341.

Nonaka H, Mori A, Ichimura M, Shindou T, Yanagawa K, Shimada J, Kase $H$ (1994b) Binding of $\left[{ }^{3} \mathrm{H}\right] \mathrm{KF} 17837 \mathrm{~S}$, a selective adenosine $\mathrm{A}_{2}$ receptor antagonist, to rat brain membranes. Mol Pharmacol $46: 817-822$.

Parkinson FE, Fredholm BB (1990) Autoradiographic evidence for G-protein coupled $A_{2}$-receptors in rat neostriatum using $\left[{ }^{3} \mathrm{H}\right] \mathrm{CGS}$ 21680 as a ligand. Naunyn Schmiedebergs Arch Pharmacol 342:85-89. Schiffmann SN, Jacobs O, Vanderhaeghen J-J (1991a) Striatal restricted adcnosinc $\mathrm{A}_{2}$ receptor (RDC8) is expressed by enkephalin but not by substance $\mathrm{P}$ neurons: an in situ hybridization histochemistry study. J Neurochem 57:1062-1067.

Schiffmann SN, Libert F, Vassart G, Dumont JE, Vanderhaeghen J-J (1990) A cloned $G$ protein-coupled protein with a distribution 
restricted to striatal medium-sized neurons. Possible relationship with D1 dopamine receptor. Brain Res 519:333-337.

Schiffmann SN, Libert F, Vassart G, Vanderhaeghen J-J (1991b) Distribution of adenosine $A_{2}$ receptor $m R N A$ in the human hrain. Neurosci Lett 130:177-181.

Shimada J, Suzuki F, Nonaka H, Ishii A, Ichikawa S (1992) (E)-1,3Dialkyl-7-methyl-8-(3,1,5-trimethoxystryl)xanthines: potent and selective adenosine $\mathrm{A}_{2}$ antagonist. J Med Chem 35:2342-2345.

Shindou T, Watanabe S, Kamata O, Yamamoto K, Nakanishi H (1994) Calcium-dependent hyperexcitability of hippocampal CA1 pyramidal cells in an in vitro slice after ethanol withdrawal of the rats. Brain Res $656: 432-436$
Suzuki F, Shimada J, Mizumoto H, Karasawa A, Kubo K, Nonaka H, Ishii A, Kawakita T (1992) Adenosine A1 antagonists. II. Structure-activity relationships on diuretic activities and protective effects against acute renal failure. J Med Chem 35:3066-3075.

Trivedi BK, Bridges AJ, Patt WC, Priebe SR, Bruns RF (1989) $\mathrm{N}^{6}$ Bicycloalkyladenosine with unusually high potency and selectivity for adenosine A1 receptor. J Med Chem 32:8-11.

Van Calker D, Müller M, Hamprecht B (1979) Adenosine regulates via different types of receptors: the accumulation of cyclic AMP in cultured brain cells. J Neurochem 33:999-1005.

Van der Kloot W (1991) The regulation of quantal size. Prog Neurobiol 36:93-130. 